\title{
Multidrug-resistant Mycobacterium tuberculosis Beijing/W genotype in Venezuela
}

Mycobacterium tuberculosis Beijing/W family, described in 1995 (van Soolingen et al., 1995), is an emerging pathogen in several areas of the world, and a predominant endemic strain in others; it is frequently associated with drug resistance (European Concerted Action on New Generation Genetic Markers and Techniques for the Epidemiology and Control of Tuberculosis, 2006). However, in Latin America little information about the prevalence of this genotype is available. Cuba and Argentina have reported Beijing genotype-infected patients, but only in Cuba has an association been found with drug resistance (Díaz et al., 1998; Morcillo et al., 2005).

In Venezuela, a country of moderate tuberculosis (TB) incidence (25 per 100000 population), the first countrywide study of drug resistance was carried out during 1998-1999. The majority (77\%) of the strains isolated in this survey were genotyped by spoligotyping and the Beijing/W genotype was not found (Aristimuño et al., 2006).

In this study we investigated the genetic profiles of a collection of 36 multidrug-resistant (MDR) M. tuberculosis isolates, cultured from smear-positive sputum of $36 \mathrm{~TB}$ cases diagnosed by the Venezuelan National Tuberculosis Programme (VNTP), during the period 2000-2004. The isolates were identified as M. tuberculosis complex using biochemical tests, and drug susceptibility testing (DST) was carried out on Lowenstein-Jensen medium by the proportion method
(Canetti et al., 1969) and the BACTEC 460 radiometric method (Siddiqi et al., 1981). Extraction of genomic DNA, spoligotyping and IS6110-RFLP were performed by standard methods (Ausubel et al., 1988; Kamerbeek et al., 1997; van Embden et al., 1993). The comparison of spoligotypes with the international spoligotype database [SpolDB4 (http://www.pasteurguadeloupe.fr:8081/SITVITDemo/ index.jsp)] showed that the isolates belonged to the following genomic families of M. tuberculosis: LAM (23, $64 \%), \mathrm{T}$ (8, $22 \%)$, Haarlem (3, $8 \%)$ and Beijing/W (2, $6 \%$ ). The two Beijing/W isolates (VEN 3748, VEN 4145) presented identical DNA fingerprinting with 17 copies of IS6110, and the same mutation conferring resistance to isoniazid (INH) (Ser315Thr in katG) and rifampicin (RIF) (Ser531Leu in rpoB). The comparison of the IS6110RFLP patterns with a set of 19 Beijing/W reference patterns representative of the Beijing genotype (Kremer et al., 2004) and with a set of $22 \mathrm{MDR}$ Beijing/W genotype isolates at UNIZAR database (Zaragoza, Spain) revealed, respectively, $85 \%$ similarity to the Beijing/W reference pattern NLA009500592 and >90\% similarity to the Beijing/W strains isolated in 1999 from two Peruvian immigrant patients (P1, P2) resident in Spain (Codina et al., 1999) (Fig. 1).

The 3748 Beijing/W strain was isolated from a 37-year-old Peruvian, human immunodeficiency virus (HIV)-negative male, resident in Caracas, Venezuela, who used to travel to and from Lima, Peru. He had been diagnosed with pulmonary TB and received non-supervised treatment. He emigrated to Venezuela with respiratory symptoms, in 2002, and received standard retreatment (VNTP); however, he was not cured and died 2 years later.

The 4145 Beijing/W strain was isolated from a 17-year-old Venezuelan, HIVnegative male, diagnosed with pulmonary TB in 2002, and resident in Caracas, who declared no travel abroad. He had not previously received anti-TB treatment and received the standard treatment for new TB cases, according to VNTP. However, his sputum was not cleared. He was then treated with a regimen that included amikacin, pyrazinamide, cycloserine, ethionamide and ofloxacin, but again the sputum was not cleared.

The VNTP prescribes for all forms of TB, with or without culture confirmation, a standardized 6 month treatment for all new TB cases, consisting of a 2 month initial phase of INH, RIF, pyrazinamide and ethambutol, followed by a phase of 4 months with INH and RIF three times a week. If a patient is not cured with this regimen the VNTP indicates culture and DST. The regimen with second line drugs is prescribed in accordance with the results of the DST.

In summary, the findings in this study document for what is believed to be the first time a cluster of two TB patients infected by Beijing/W genotype MDR strains in Venezuela. The high similarity observed with the fingerprints of the isolates from Peruvian immigrant patients resident in Spain suggest that the first
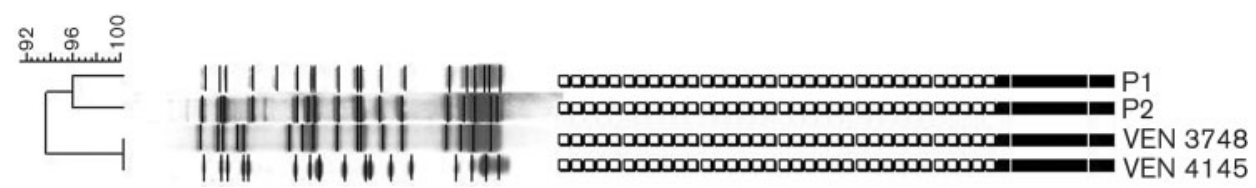

Fig. 1. Dendrogram of IS6110-RFLP and spoligotyping of the clinical isolates from Venezuelan (VEN 3748, VEN 4145) and Peruvian patients ( $\mathrm{P} 1, \mathrm{P} 2)$. 
strain isolated could have been imported from Peru, and that further local transmission as MDR TB occurred. Our data confirm the importance of the molecular typing of MDR strains in order to monitor movement, change and expansion of emerging genotypes.

\section{Acknowledgements}

This work has been partially financed by a grant from the Universidad Centroccidental Lisandro Alvarado, Venezuela, and Fondo de Investigaciones Sanitarias, Spain $(06 / 1624)$.

\section{Liselotte Aristimuño, ${ }^{1,2}$ \\ Mercedes España, ${ }^{3}$ Alexis Guilarte, ${ }^{3}$ Carmen Ramírez, ${ }^{3}$ Janet Rojas, ${ }^{3}$ Patricia Gavín, ${ }^{2,4}$ Ana I. López-Calleja, ${ }^{2,4}$ M. Antonia Lezcano, 2,4 \\ M. José Revillo, ${ }^{2,4}$ Alberto Cebollada, ${ }^{2}$ Carlos Martín ${ }^{2}$ and Sofía Samper ${ }^{2,4}$}

${ }^{1}$ Escuela de Medicina, Universidad Centroccidental Lisandro Alvarado, Venezuela

${ }^{2}$ Grupo de Genética de Micobacterias, Departamento de Microbiología, Medicina Preventiva y Salud Pública, Universidad de Zaragoza, Spain

${ }^{3}$ Programa Nacional Integrado de Control de la Tuberculosis and Laboratorio Nacional de Referencia de Bacteriología de la Tuberculosis, Ministerio de Salud, Venezuela

${ }^{4}$ Servicio de Microbiología Hospital Universitario Miguel Servet, Instituto
Aragonés de Ciencias de la Salud, Zaragoza, Spain

\section{Correspondence: Sofía Samper}

(ssamper@salud.aragon.es)

Aristimuño, L., Armengol, R., Cebollada, A., España, M., Guilarte, A., Lafoz, C., Lezcano, M. A., Martín, C., Ramirez, C. \& other authors (2006). Molecular characterization of Mycobacterium tuberculosis isolates in the First National Survey Anti-tuberculosis Drug Resistance from Venezuela. BMC Microbiol 6, 90.

Ausubel, F. M., Brent, R., Kingston, R. E., Moore, D. D., Seidman, J. G., Smith, J. A. \& Struhl, K. (1988). Current Protocols in Molecular Biology. New York: Green Publishing \& Wiley Interscience.

Canetti, G., Fox, W., Khomenko, A., Mahler, H. T., Menon, N. K., Mitchison, D. A., Rist, N. \& Smelev, N. A. (1969). Advances in techniques of testing mycobacterial drug sensitivity and the use of sensitivity tests in tuberculosis control programmes. Bull World Health Organ 41, 21-43.

Codina, G., Vidal, R., Martín-Casabona, N., Miravitlles, M. \& Martín, C. (1999). Multidrugresistant tuberculosis caused by 'W'-related strains in three immunocompetent foreign-born patients. Int J Tuberc Lung Dis 3, 82.

Díaz, R., Kremer, K., de Haas, P. E., Gómez, R. I., Marrero, A., Valdivia, J. A., van Embden, J. D. \& van Soolingen, D. (1998). Molecular epidemiology of tuberculosis in Cuba outside of Havana, July 1994-June 1995: utility of spoligotyping versus IS6110 restriction fragment length polymorphism. Int J Tuberc Lung Dis 2, 743-750.

European Concerted Action on New Generation Genetic Markers and Techniques for the Epidemiology and Control of Tuberculosis (2006). Beijing/W genotype
Mycobacterium tuberculosis and drug resistance. Emerg Infect Dis 12, 736-743.

Kamerbeek, J., Schouls, L., Kolk, A., van Agterveld, M., van Soolingen, D., Kuijper, S., Bunschoten, A., Molhuizen, H., Shaw, R. \& other authors (1997). Simultaneous detection and strain differentiation of Mycobacterium tuberculosis for diagnosis and epidemiology. $J$ Clin Microbiol 35, 907-914.

Kremer, K., Glynn, J. R., Lillebaek, T., Niemann, S. Kurepina, N. E., Kreiswirth, B. N., Bifani, P. J. \& van Soolingen, D. (2004). Definition of the Beijing/W lineage of Mycobacterium tuberculosis on the basis of genetic markers. J Clin Microbiol 42, 4040-4049.

Morcillo, N., Giulio, D., Chirico, C., Kuriger, A., Dolmann, A., Alito, A., Zumárraga, M., van Soolingen, D., Kremer, K. \& Cataldi, A. (2005). First description of Mycobacterium tuberculosis Beijing genotype in Argentina. Rev Argent Microbiol 37, 92-95.

Siddiqi, S. H., Libonati, J. P. \& Middlebrook, G. (1981). Evaluation of a rapid radiometric method for drug susceptibility testing of Mycobacterium tuberculosis. J Clin Microbiol 13, 908-912.

van Embden, J. D. A., Cave, M. D., Crawford, J. T., Dale, J. W., Eisenach, K. D., Gicquel, B., Hermans, P., Martin, C., McAdam, R. \& other authors (1993). Strain identification of Mycobacterium tuberculosis by DNA fingerprinting: recommendations for a standardized methodology. J Clin Microbiol 31, 406-409.

van Soolingen, D., Qian, L., de Haas, P. E., Douglas, J. T., Traore, H., Portaels, F., Qing, H. Z., Enkhsaikan, D., Nymadawa, P. \& van Embden, J. D. (1995). Predominance of a single genotype of Mycobacterium tuberculosis in countries of East Asia. J Clin Microbiol 33, 32343238. 